\title{
O PODER E O POLÍTICO NA TEORIA DOS CAMPOS
}

Céli Regina Jardim Pinto*

SÍNTESE - O presente texto não pretende ser um artigo analítico sobre Bourdieu mas um ensaio escrito da perspectiva de uma cientista política sobre as possibilidades abertas pela teoria desenvolvida pelo sociólogo francês para o estudo dos fenômenos da política. Com este propósito trabalharei com as noções de campo e capitais.
ABSTRACT - The present text doesn't intend to be analytic article about Bourdieu but a written practice of a politic scientist's perspective about the possibilities opened by the theory developed by the French sociologist to the studies of the political phenomena. With this purpose I'll work with the notions of field and funds.

O presente texto não pretende ser um artigo analítico sobre Bourdieu mas um ensaio escrito da perspectiva de uma cientista política sobre as possibilidades abertas pela teoria desenvolvida pelo sociólogo francês para o estudo dos fenômenos da política. Com este propósito trabalharei com as noções de campo e capitais.

As páginas que se seguem derivaram-se de anotações de uma aula proferida em um curso de extensão sobre Bourdieu e guarda daquele momento uma linguagem coloquial. Naquela oportunidade meu objetivo era antes de tudo fazer um exercício buscando instrumentos para a análise da política. Mantenho agora a mesma pretensão. Nestes tempos de pós-modernidade a moda parece ser a construção de teorias que explicam um único caso. Teóricos e seus estudiosos reivindicam a criação de uma teoria para cada caso em análise. Difícil aqui perceber a linha divisória entre o rigorismo científico, uma certa irresponsabilidade ou o puro modismo. Penso que, se por um lado, não se pode mais aceitar teorias guarda-chuvas capazes de grandes explicações generalizantes, por outro, não se pode abrir mão de buscar na produção teórica sociológica noções capazes de darem conta de fenômenos um pouco mais abrangentes do que aqueles que fundam a própria teoria. $\mathrm{E}$ este é aqui o meu propósito.

Buscar uma definição de poder na obra de Bourdieu envolve trabalhar com duas noções fundamentais de seu aporte teórico, capital e campo. Na verdade poder-se-ia começar a discutir estas noções a partir de duas afirmações bastante simples: 1. o poder carece de identidade própria e só pode ser entendido como um evento decorrente de agentes com capital; 2 . o poder dos agentes resulta do volu-

* Universidade Federal do Rio Grande do Sul, UFRGS. 
me e qualidade dos capitais em um campo de luta, portanto, só faz sentido analisar os fenômenos do poder no interior do campo.

Como poderemos perceber ao longo da explanação, os conceitos desenvolvidos por Bourdieu possuem um grande rigor por conta de cuidadosas definições. Com isto em mente cabe uma questão com refêrencia à relação poder-campo: se as relações de poder só acontecem dentro de um campo, toda vez que é identificada uma relação de poder estamos frente a um campo? Se a resposta é positiva deriva-se que se não conseguimos identificar este campo, estamos frente a duas possibilidades: ou não se trata de relações de poder ou houve uma falha na identificação do campo. Bourdieu talvez não considerasse apenas estas duas possibilidades, na medida em que poderia argumentar que a relação poder-campo só acontece em organizações sociais complexas e altamente diferenciadas. Menos por pretender ser intérprete fiel de Bourdieu e mais pelo propósito de buscar na sua proposta teórica instrumentos para a análise de soceidades distintas da francesa, defendo aqui que é possível indentificar o campo e seus limites mesmo em sociedades onde exite uma aparente promiscuidade de interesses e capitais.

Para avançarmos nesta questão vale buscar nas palavras do autor as características do campo: "espaço estruturado de posições ou de postos onde as propriedades dependem de sua posição dentro destes espaços e que podem ser analisados independentemente das características de seus ocupantes".

O campo é caracterizado por quatro leis fundamentais: 1. para que exista um campo deve existir interesses especificos que são irredutíveis, isto é, nenhum outro campo é capaz de supri-los; 2 . todo o campo é regido por regras e leis de funcionamento e para que funcione os agentes devem estar predispostos a aceitá-las e serem dotados de capacidades para entendê-las; 3. a estrutura do campo é definida pelo estado da luta e pela qualidade e quantidade de capital distribuídos entre os agentes; 4 . todos os agentes de um campo tem pelo menos um interesse comum: a própria existência do campo (Bourdieu, 1983, p. 89).

A teoria dos campos em Bourdieu, como pode ser visto nestes breves pontos, é construida com rigor, o que torna a identificação de campos um trabalho que envolve grande cuidado metodológico. É evidente que em sociedades mais estratificadas e com sistemas políticos mais estáveis como a francesa a identificação dos campos, de seus limites, de seu funcionamento é mais clara que em sociedades menos organizadas como a do Brasil. Ao mesmo tempo não se pode assumir a quantidade de formalismo como a prova ou não da existência de campos e de interesses irredutiveis. Talvez o reconhecimento e análise da promiscuidade dos campos em sociedades como a brasileira permita romper quando da análise de sociedades desenvolvidas, com uma pretensa pureza na conceituação de Bourdieu.

Com o propósito de avançar na teoria dos campos uma nova questão se coloca: pelo que se luta em um campo? Luta-se para impor uma vontade, uma visão de mundo, os interesses de uns sobre os outros. Luta-se enfim para se ter poder dentro do campo. E, por paradoxal que possa parecer, só se luta porque já se tem poder. Quem não tem nenhum poder, nenhum capital dentro do campo não tem interesses irredutiveis e, portanto, não tem nem razão, nem cacife para pertencer a um campo. Por mais destituído de poder que possa parecer um agente no interior do campo, ainda assim o analista deve se perguntar por que ele é admitido no 
campo, por que ele ali permanece. Poder-se-ia dizer que permanece porque não tem poder para sair. Isto pode até ser verdade, quando se trata de pensar um indivíduo em particular e suas razões pessoais, mas quando se pensa na sua posição relacional no campo e é com este fenômeno que Bourdieu está preocupado, sua permanência se dá pelo capital que acumula, mesmo que seja independente de sua vontade.

A admissão e a permanência dos agentes no campo se dá cumprindo duas exigências: ter os mesmos interesses irredutíveis do conjunto dos agentes em luta, isto é, interesses que só poderão ser potencialmente satisfeitos no campo; ter a disposição de cumprir as regras de funcionamento do campo.

O campo estrutura-se pelo estado da relação de força entre os agentes. A matéria-prima desta luta é o capital de cada agente que varia tanto quanto a quantidade como quanto a qualidade. Capital é definido por Bourdieu como "uma relação social, isto é, uma energia social que não existe e não produz seus efeitos a não ser dentro do campo onde ele se produz e se reproduz" (Bourdieu, 1979, p. 127).

Podemos dizer, portanto, que o capital é o conteúdo do poder em uma dada relação de forças. Bourdieu discrimina uma série de capitais, capital cultural, capital econômico, capital social, capital religioso. Estes capitais só terão sentido em uma dada relação: um mesmo capital tem valores diferentes em campos diferentes e pode inclusive ter um grande valor em um campo e absolutamente nenhum em outro.

Pensemos, como exemplo, o campo intelectual e o capital cultural: um escritor ou um cientista não tem poder neste campo por ser herdeiro de uma grande fortuna. Um agente com muito dinheiro mas sem conhecimento científico jamais será reconhecido como intelectual. Seu dinheiro não é no interior deste campo um capital . O mesmo poder-se-ia dizer do campo financeiro: um grande cientista ou escritor, por mais reconhecido que seja, não consegue ter poder a partir deste tipo de capital neste campo.

A questão não é, no entanto, tão simples e não se esgota nos exemplos acima. Mesmo para o leitor menos atento é fácil perceber a possibilidade de conversão de capital. Não se trata aqui, e isto deve ficar bastante claro, de criar um novo tipo de determinismo econômico, aceitando que o capital econômico possa ser convertido em outras formas de capital. Sem deixar de apontar que no mundo capitalista há uma grande preponderância do capital econômico, o que quero enfatizar, entretanto, é outro aspecto: isto é, a possibilidade dos agentes acumularem tal quantidade de capital em um determinado campo que possibilite um trânsito de um campo ao outro através da conversão. $\mathrm{O}$ caso do trânsito do campo da política para o campo da produção cultural, ou vice versa, é bastante comum. O mesmo acontecendo entre sub-campos da produção cultural. No primeiro caso não é difícil dar-se conta que um político de grande popularidade tem mais facilidade de encontrar espaço para expor seus quadros em uma galeria de arte do que um cidadão anônimo. Da mesma forma, um ator de popularidade encontrará muito mais espaço para satisfazer sua vontade de entrar no campo da política do que um agente cuja atividade não pressuponha popularidade e exposição pública.

A relação entre os capitais não se dá apenas pela conversão, mas também pela possibilidade de adquirir um tipo de capital em decorrência de já ter outro. Bour- 
dieu ao discutir as formas de capital cultural chama a atenção para o fato de que quanto mais este exige um tempo longo para ser adquirido, somado à necessidade de freqüência a instituições altamente especializadas, mais o capital econômico torna-se pré-requisito (Bourdieu 1964, p. 69).

No que concerne ao sub-campo da produção cultural, basta ligar a televisão para que se possa ver uma série de atores famosos tendo espaços em gravadoras e programas de música para cantar, em que pese a total ausência de voz. De outra forma, pode-se encontrar cantores famosos declamando infantilmente papéis mal decorados em telenovelas. O mesmo acontece com o tornar-se escritor. Muitas vezes é mais importante ter um programa de televisão de sucesso do que ter talento literário para ser publicado por uma grande editora. Não se trata de nenhum dos casos de pura malícia de empresários de televisão, editoras de espaços de arte ou mesmo dos agentes, mas de verdadeiro acúmulo de capital que provoca uma transformação na natureza original do capital exigido em cada campo.

Em um mundo dominado pela mídia e com grande apelo para o consumo imediato e descartável, a popularidade passou a ser um capital altamente disputável pelos diversos campos e transferível de um campo para o outro. Alguém que tem popularidade em um campo tem facilidade de transitar de um campo para outro, o que desvaloriza no interior do campo os agentes que têm uma grande quantidade de capital originário do próprio campo. Um exemplo flagrante é a perda de poder do militante partidário cujo capital origina-se apenas do fato de ser militante vis-àvis a pastores evangélicos "comunicadores" e mesmo atores variados.

Ao analisarmos as várias questões envolvidas na noção de capital, devemos ter sempre presente que os capitais em que pesem os processos de transferência apontados acima, estão sempre atuando no espaço limitado do campo. Espaço este que tem regras a serem cumpridas e interesses a serem preservados. Porque o capital para se reproduzir necessita do campo; os agentes no interior do campo tendem a lutar por sua preservação. Daí o aspecto conservador deste espaço.

Um exemplo bastante claro da condição conservadora do campo pode ser visto na lógica do campo político da democracia parlamentar representativa. Quando militantes de extrema esquerda acusam seus antigos companheiros de terem se acomodado ou terem se tornado de direita quando crescem as chances eleitorais de seus partidos, não estão longe da verdade. Os partidos de esquerda quando se tornam eleitoralmente fortes e atuantes no parlamento, passam a defender as regras do jogo deste parlamento e do próprio sistema político como um todo, na medida em que sua reprodução garante a própria reprodução dos agentes. No Brasil, os desencontros entre os militantes, a burocracia e os parlamentares do PT, que muitas vezes chegam às páginas dos jornais, são bons exemplos da tendência que estou apontando.

Até aqui me preocupei em apontar as caracteristicas constituidoras do campo e a dinâmica dos capitais em seu interior. Cabe agora discutir a forma como os agentes transformam capital em poder e para isso se faz necessário introduzir o conceito de capital simbólico ou poder simbólico. Este é o resultado da naturalização dos diversos capitais que deixam de ser percebidos como resultados de relações de dominação e passam a ser aceitos como legítimos. O capital simbólico encobre os outros capitais. A respeito dele Boúrdieu afirma: "O poder simbólico, po- 
der subordinado, é uma forma transformada, quer dizer, irreconhecivel, transfigurada e legitimada, das outras formas de poder" (Bourdieu, 1989, p. 15).

A luta política é a luta simbólica por excelência, pois seu principal objetivo é converter, é o fazer crer que sua proposta é a melhor para todos: transformar os interesses localizados de grupo, isto é, de classe ou fração de classe, em interesses gerais. Bourdieu define as lutas simbólicas entre as classes ou frações como aquelas que têm como objetivo imporem a definição do mundo mais conforme com seus interesses.

A centralidade do poder simbólico deve sempre ser considerada na análise visà-vis aos demais poderes, na medida em que é considerado um poder dependente, isto é, uma conversão. Não parece haver aqui nenhuma determinação, isto é, a presença de um poder material não pressupõe poder simbólico, mas, por outro lado, não existe poder simbólico sem um outro tipo de poder.

$\mathrm{O}$ que estou tratando de enfatizar aparece exemplificado na obra de Bourdieu quando descreve o capitalismo "como uma economia que se define como recusando a reconhecer a verdade 'objetiva' de práticas 'econômicas', isto é, a lei do interesse e do cálculo egoísta, o capital econômico não pode agir a não ser que se previna de ser reconhecido ao preço de uma reconversão própria, para tornar-se irreconhecivel o verdadeiro princípio de sua eficácia: o capital simbólico é o capital denegado, reconhecido como legítimo, isto é, não reconhecido como capital" (Bourdieu, 1980 p. 200).

Neste fim de século em que o consumo suntuário tornou-se um valor completamente desassociado da utilidade inicial dos produtos, onde o êxito pessoal tornou-se um valor que se instalou mesmo entre aqueles grupos mais resistentes a ele no interior da sociedade, podemos dizer que estamos frente a um momento privilegiado de sucesso de reconversão do capital econômico em simbólico.

Tendo traçado este quadro geral das noções de campo e capital gostaria de me deter nas páginas restantes na questão específica do campo da política.

Quando se fala de política fala-se de um campo de poder por excelência. Em que este campo de poder se distingue dos demais campos, uma vez que em última instância todos os campos envolvem luta e força? Distingue-se por ser um espaço de luta pelo poder em si "entre detentores de poderes diferentes, é um espaço de jogo onde os agentes e as instituições que têm em comum o fato de possuírem uma quantidade de capital específico sufićiente para ocupar as posições dominantes no seio de seus respectivos campos de luta afrontam-se em estratégias destinadas a conservar ou a transformar esta relação de força" (Bourdieu 1990, p. 375)

Um aspecto peculiar do campo político é a sua indefinição quanto ao seu próprio caráter. Os agentes chegam até ele porque acumulam capital em outros campos e necessitam dele para que seu campo de origem se reproduza. Dentro desta lógica a questão que se coloca é a de que tipo de interesse próprio e irredutível que constitui o campo político. Parece que se pode apontar dois tipos de interesses próprios e irredutiveis: um decorrente da própria existência do campo, isto é, o interesse irredutivel seria sua própria existência que garantiria a manutenção de poderes nos campos de origem dos agentes, daí inclusive o estabelecimento de regras rígidas tanto no que concerne às formas de jogar como nas formas de acesso. Um segundo tipo de interesse é decorrência de formas específicas de competição polí- 
tica: estou me referindo aos interesses constituidos em decorrência do próprio jogo e materializado no poder das burocracias de estado e de partidos, definidoras de regimes totalitários, mas nunca totalmente ausentes no campo político em geral.

Para que os agentes do campo político alcancem seus objetivos necessitam produzir mercadorias para o cidadão eleitor; daí ser o campo "o lugar em que se geram na concorrência entre os agentes que nele se acham envolvidos, produtos políticos, problemas, análises, comentários, conceitos, acontecimentos entre os quais os cidadãos comuns, reduzidos ao estatuto de 'consumidores' devem escolher com probabilidade de mal entendidos, quanto mais afastados estiverem do lugar de produção" (Bourdieu. 1989, p. 165).

A distinção entre campo de produção e campo de consumo é especialmente interessante para o entendimento dos fenômenos políticos. O campo da produção é o campo propriamente político, onde os diversos agentes lutam para tomar o estado através da imposição de sua visão de mundo, imposição esta legitimada pelo fazer crer. Neste campo, os diversos capitais se transformam em capital político que em uma democracia pode ser traduzido pela capacidade dos agentes de conseguir votos. Aqui fica muito clara a transferência de capital de um campo ao outro. A capacidade de conseguir voto deriva-se do capital simbólico dos agentes e este, da conversão de capitais acumulados e transformados em poder, na grande maioria das vezes em outros campos que não o político. Talvez o único capital eminentemente político é o derivado da militância, cada vez menos presente nas democracias liberais do fim do século.

Dentro da lógica de mercado assumida por Bourdieu do campo de produção e do campo de consumo, a questão que se impõe diz respeito à mercadoria oferecida pelo primeiro ao segundo. E é neste particular que a centralidade do capital simbólico no campo político fica claro. O campo político como campo de produção produz visões de mundo, cada grupo, classe ou fração de classe trata de transformar seus interesses particulares em interesses gerais. Cada fração trata de fazer crer ao campo consumidor que seu produto vai preencher melhor as suas necessidades. Neste sentido o capital político é o capital simbólico por excelência.

Na medida em que cada vez mais o capital político é um capital convertido, algumas conseqüências daí se derivam: primeiro, que o campo da política deixa de ser um campo produtor stricto sensu para ser um campo de reconversão; segundo, que não sendo um campo de produção a "mercadoria" política tende a ter minimizado seu conteúdo ético, idealista e utópico em favor de visões de mundo mais pragmáticas e imediatistas; terceiro, os agentes do campo de consumo tendem a cada vez mais ver a política como um espaço para especialistas.

Para concluir esta aula-ensaio gostaria de sugerir algumas possibilidades de análise a partir do que foi visto aqui da situação em relação à política brasileira. Não pretendo criar um modelito, nem tão pouco instrumentalizar a teoria bourdieuana. Apenas pretenđo argumentar que a formalização nela encontrada não é limite para ser aplicada em realidades como a brasileira, mas ao contrário, é um instrumento particularmente útil para decantar alguns fenômenos que se apresentam de forma bastante nebulosa.

Uma questão bastante complicada de analisar no Brasil é a composição do capital dos agentes nos campos de poder, quer seja ele político, quer de outra nature- 
za. Enquanto Bourdieu parece ter muito bem definido em que campos cabe qual capital, no caso brasileiro isto não está claro. Se existe, como chamei anteriormente, uma promiscuidade de capitais e de campos, identificar a composição dos capitais em cada campo e os interesses irredutíveis de cada campo permitiria traçar uma radiografia bastante profícua das relações de poder na política .

Tendo tido as terras brasileiras uma forte tradição clientelista em sua história política, tendo passado por experiências populistas e autoritárias e estando agora ensaiando viver em um regime democrático, seria bastante interessante analisar a composição do capital do campo político historicamente e até a própria constituição do campo enquanto espaço de interesses irredutíveis ao longo do tempo.

Dentro desta mesma problemática geral uma questão particularmente interessante de discutir em relação ao Brasil é a da reconversão de capital ou da possibilidade de adquirir um capital na medida em que se é possuidor de outro. Mesmo sendo problemático, seria possivel no Brasil identificar ainda que quase como metáfora, o campo da corrupção onde seria possivel encontrar interesses irredutíveis, regras claras do jogo e agentes com predisposição para jogar. A análise da composição do capital deste campo seria extremamente importante para mapear os focos e as fronteiras do campo, tanto com o campo político tradicional, como com o campo da contraversão mais completamente representado pelo narcotráfico.

As propostas de investigação poderiam se multiplicar. Não é meu propósito listar questões para serem resolvidas pela teoria de Bourdieu, mas apenas sugerir possibilidades, com perdão dos especialistas.

\section{Referências bibliográficas}

BOURDIEU. Pierre. La Distinction. Paris: De Minuit, 1979.

- Le Sens Praticque. Paris: De Minuit, 1980.

—. Questōes de Sociologia. Rio de Janeiro: Marco Zero, 1983.

—_ . O Poder Simbólico. Rio de Janeiro, 1989.

—_ La Noblesse D'État. Paris: De Minuit, 1989. 